\title{
Effect of a surgical observership on the perceptions and career choices of preclinical medical students: a mixed-methods study
}

\author{
Maureen Thivierge-Southidara, \\ MD \\ Mathieu Courchesne, MD \\ Steven Bonneau \\ Michel Carrier, MD \\ Margaret Henri, MD
}

Presented at the Canadian Conference for the Advancement of Surgical Education, Sept. 25-26, 2019, Ottawa, Ont.

Accepted Jan. 11, 2021

\author{
Correspondence to: \\ M. Thivierge-Southidara \\ Department of Surgery \\ Université de Montréal \\ 2900, boul Édouard-Montpetit \\ Montréal OC H3T 1J4 \\ maureen.thivierge-southidara@ \\ umontreal.ca
}

Cite as: Can J Surg 2022 January 11; 65(1). doi: $10.1503 /$ cjs. 019419
Background: Medical students are increasingly choosing nonsurgical specialties; observership programs can address factors influencing them toward surgical careers by allowing preclerkship exposure and mentorship, and correcting misconceptions. The aims of this study were to assess the influence of a peer-led observership program at the Université de Montréal on the career choices of preclinical medical students and to determine the factors associated with a positive observership experience.

Methods: We used a quasi-experimental convergent mixed-methods questionnaire design. From Nov. 19 to Dec. 31, 2018, and Mar. 1 to Apr. 4, 2019, all medical students participating in the observership program were eligible for the study; there were no ineligibility criteria. Using a prospective purposive sampling method, we recruited students via the email sent to confirm their observership. In the week after their observership, we invited the students by email to complete a postintervention survey. We used nonparametric tests to evaluate the impact of the observership on participants' career choices and an inductive data-driven thematic analysis to analyze their responses.

Results: Of the 204 students who participated, 157 provided consent, of whom 85 $(54.1 \%)$ completed questionnaires both before and after the observership. The majority of participants were interested in a surgical specialty before (72 [85\%]) and after $(68[84 \%])$ the observership. There was no significant change in the students' choices of surgical specialties after the observership. However, most (68 [81\%]) reported being more interested in a surgical career as a result of the observership, which allowed them to see that the type of practice they considered was congruent with a surgical career. Their perceptions of the field of surgery became positive, particularly regarding its pace and atmosphere and the humanistic patient-doctor relationship it required. The experience was influenced by surgeons' and teams' attitudes toward students, knowledge-sharing and quality of exposure. Participants mentioned that their willingness to participate was in part responsible for the success of their experience.

Conclusion: This observership program allowed an early, positive introduction of students to surgery while challenging stereotypes. It provided a better understanding of surgery, enabling participants to consider this field and potentially influencing their residency application.

Contexte: De plus en plus d'étudiants en médecine choisissent des spécialités non chirurgicales; les stages d'observation peuvent servir à leur rendre la carrière de chirurgien plus attirante en leur offrant une exposition et un mentorat précliniques et en corrigeant certaines idées préconçues. Cette étude avait pour but d'évaluer l'influence d'un stage d'observation mené par des pairs à l'Université de Montréal sur les choix de carrière chez les étudiants en médecine à l'étape préclinique et déterminer quels facteurs sont associés à une expérience positive lors du stage d'observation.

Méthodes: Nous avons utilisé un type de questionnaire à méthodes mixtes convergent quasi-expérimental. Du 19 novembre au 31 décembre 2018 et du $1^{\text {er }}$ mars au 4 avril 2019, tous les étudiants en médecine participant au stage d'observation étaient admissibles à l'étude; il n'y avait aucun critère d'exclusion. À l'aide d'une méthode d'échantillonnage dirigé prospectif, nous avons recruté les étudiants à même le courriel de confirmation de leur stage d'observation. La semaine suivant leur stage d'observation, nous les avons invités par courriel à répondre à un questionnaire. Nous avons utilisé des tests non paramétriques pour mesurer l'impact 
du stage d'observation sur leurs choix de carrière et une analyse thématique inductive guidée par des données pour analyser leurs réponses.

\begin{abstract}
Résultats: Parmi les 204 étudiants qui ont participé, 157 ont fourni leur consentement, dont $85(54,1 \%)$ ont répondu aux questionnaires avant et après le stage d'observation. La majorité des participants étaient intéressés par une spécialité chirurgicale avant (72 [85\%]) et après $(68$ [84\%]) le stage d'observation. On n'a noté aucun changement significatif dans les choix de spécialité chirurgicale des étudiants après le stage d'observation. Par contre, la plupart (68 [81\%]) se sont dits plus intéressés par une carrière en chirurgie par suite du stage d'observation, qui leur a permis de voir que le type de pratique auquel ils aspiraient s'harmonisait bien avec une carrière en chirurgie. Leurs perceptions du domaine de la chirurgie sont devenues positives, particulièrement au plan du rythme, de l'ambiance et du lien patient-médecin empreint d'humanité qui est requis. Leur expérience a été influencée par l'attitude des chirurgiens et des équipes qui les ont accueillis, par le partage des connaissances et la qualité de leur présence. Les participants ont mentionné que leur volonté de participer était en partie responsable de la réussite de leur expérience.
\end{abstract}

Conclusion: Pour les étudiants, ce stage d'observation a constitué une introduction positive au milieu chirurgical tout en ébranlant leurs préjugés. Il leur a permis de mieux comprendre ce qu'est la chirurgie et d'envisager de faire carrière dans ce domaine, et pourrait avoir influé sur leur choix de résidence.

A $\mathrm{n}$ increasing number of residents are choosing nonsurgical specialties, a trend explained mainly by residents' desire for more control over their lifestyle. ${ }^{1-3}$ The decreased number of applicants in surgical specialties is leading to a higher number of unfilled positions in the United States. ${ }^{1}$ This trend can also be observed in Canada, although the number of surgical applicants still outranks the number of positions to be filled, as it occurs in accordance with the diminished number of positions available in surgical specialties. ${ }^{4-6}$ Data from the Canadian Resident Matching Service (CaRMS) show a reduction in applicants' ranking surgical residencies as a first choice from $24.7 \%$ in 1998 , to $17.2 \%$ in 2008, to $15.4 \%$ in 2018. ${ }^{2,5}$ Although the decreasing interest in surgical specialties appears less alarming in Canada, this problem should be addressed as early as possible by surgical programs.

Factors identified as influencing students to select surgical careers include personal preferences, such as the importance of lifestyle and income, exposure to a variety of procedures during clerkship and learning in community hospitals. ${ }^{2,7}$ Three factors that could be addressed by student initiatives have been identified: preclerkship exposure, mentorship and perceptions surrounding the field of surgery. ${ }^{2,7}$

At our institution, it was believed that a peer-led initiative by the surgery interest group - the Groupe d'intérêt en chirurgie de l'Université de Montréal (GICUM) could have a positive influence on those factors. The GICUM was founded in 2010 by students and for students with the mission to expose medical students to surgery as early as the preclinical years. It now has more than 500 registered students as members. Among other activities, the GICUM supports privileged links between surgeons and medical students by overseeing a large observership program that allows students to follow surgeons for a day and thus be exposed to many aspects of their practice. The observerships are designed for students to closely observe a surgeon for a work day without being directly involved in patient care, allowing them to be exposed to a variety of medical interventions (depending on the type of exposure selected), as well as the daily routine of their preceptor. We believe this early exposure can be used to promote interest in surgery.

The primary aim of this study was to assess the influence of the observership program offered by the GICUM on the career choices of preclinical medical students. We hypothesized that the first contact with the field is crucial in influencing medical students toward surgical careers. Therefore, the second objective of this study was to determine the factors associated with a positive observership experience.

\section{Methods}

\section{Observership program}

The observership program is offered twice a year to preclinical and premedical students. The GICUM contacts every surgeon affiliated with the university's Department of Surgery by email and asks them to indicate their availability to receive preclinical medical students during 1 or more time slots. Subsequently, preclinical medical students subscribed to the GICUM's contact list receive an email with an invitation to participate in the observership program. The email contains a link to a dynamic platform allowing them to choose their observership on a firstcome, first-served basis. Students are invited to select an observership based on availability, hospital, surgical specialty, type of exposure (outpatient clinic, operating room, on-call day, scope, minor surgery) and duration (half-day or full day). Once the student has selected an observership, 
the GICUM contacts them to confirm their observership and connects them with the participating surgeon. The identity of the surgeon is not shared with the student before then to prevent selection bias.

\section{Study design}

We used a quasi-experimental, before-after, convergent mixed-method questionnaire study design to explore the impact of the observership program (Figure 1). ${ }^{8}$ From Nov. 19 to Dec. 31, 2018, and Mar. 1 to Apr. 4, 2019, all medical students participating in the observership program were eligible for the study; there were no ineligibility criteria. Using a prospective purposive sampling method, we recruited students via the email sent to confirm their observership. This communication contained information about the project, a consent form, a unique identifier and a preintervention questionnaire.

In the week after their observership, we invited the students by email to complete a postintervention survey.

\section{Data collection instruments}

\section{Quantitative}

The preintervention quantitative survey consisted of $2 \mathrm{sec}-$ tions. The first section (4 items) collected sociodemo- graphic data (sex, age, level of training, prior exposure to an observership), and the second section (1 item) asked about the specialties students were currently interested in through a multiple-choice question. Data on the specialty observed, type of observership, duration, hospital and the assigned surgeon were collected.

The postintervention survey consisted of 3 sections. The first section (4 items) collected the same sociodemographic data as in the preintervention survey. The second section ( 2 items) collected data on the specialties of current interest through a multiple-choice question and the perceived impact of the observership on students' career choices by means of a semantic differential 5-point scale from 1 ("Refuted my choice for a surgical career") to 5 ("Confirmed my choice for a surgical career"). The third section (3 items) assessed students' global appreciation of the observership via a 5 -point scale from 1 ("Hated") to 5 ("Loved"). In addition, yes/no questions were used to evaluate whether the observership had confirmed students' perceptions of the surgical domain and whether they had achieved their personal goals concerning their observership.

\section{Qualitative}

A prior qualitative pilot study allowed identification of major components that underline the experience of a surgical observership through a thematic analysis of medical

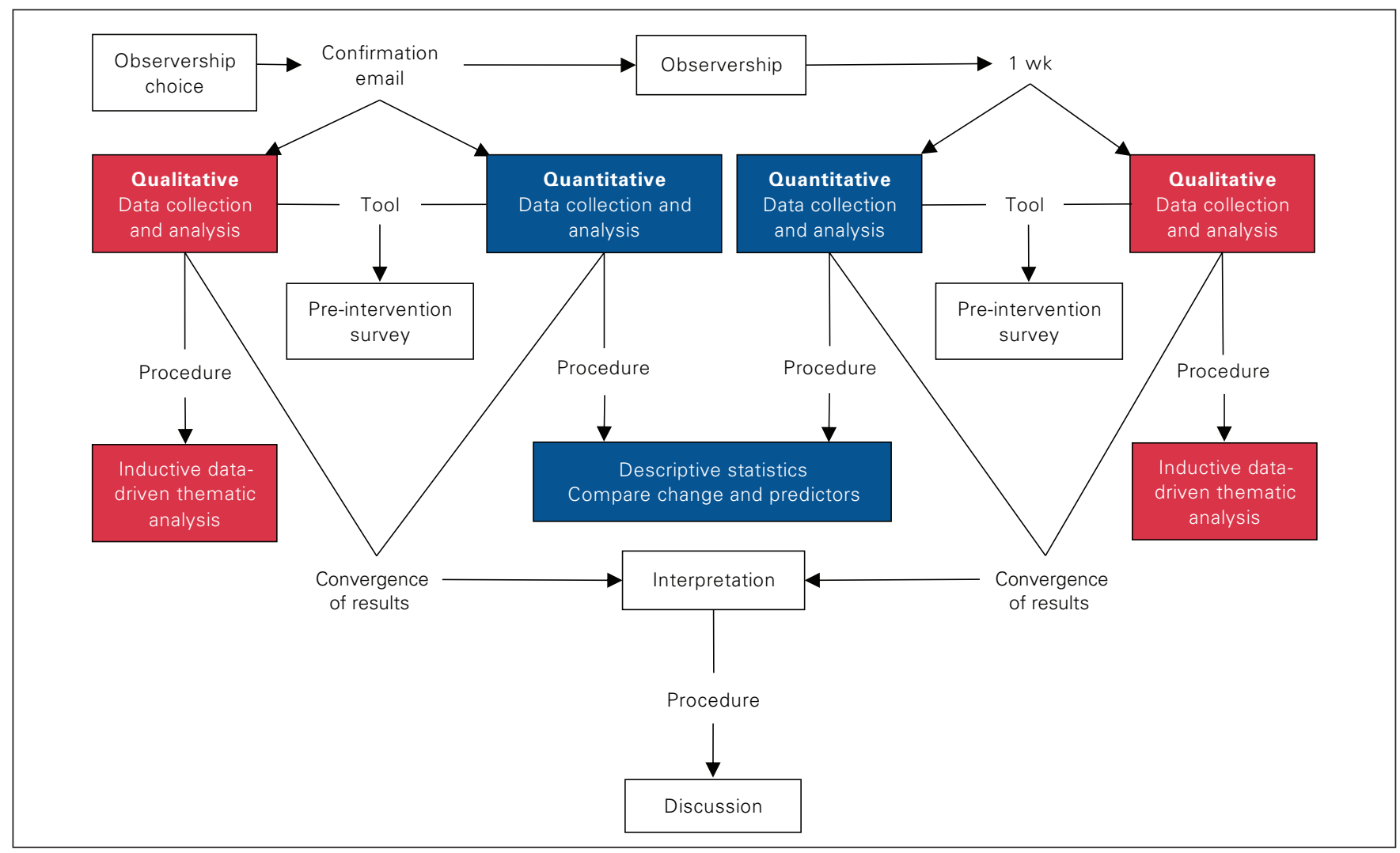

Fig. 1. Quasi-experimental convergent mixed-method design. This design follows Creswell and Plano Clark's ${ }^{8}$ conventions for the drawing of mixed-method design diagrams. 
students' written comments. We transformed these components into open-ended questions that were included in the surveys. In the preintervention survey, students were invited to share their learning objectives, perceptions of the surgical domain and concerns regarding their observership. In the postintervention survey, students were invited to share the impact of the observership on these items. They were also asked to share factors they believed were important for their career choice and for a positive observership experience. Key takeaways and suggested improvements were also elicited.

\section{Data analysis}

The data were first analyzed separately and were then merged for the discussion (Figure 1). ${ }^{8}$ Data for students who completed only the pre- or postintervention questionnaire were excluded from analysis.

\section{Quantitative}

We first assessed the observerships that were offered to and chosen by students using the $\chi^{2}$ test. We then assessed students' characteristics using the $\chi^{2}$ test and Student $t$ test to compare our sample to those who were excluded. We used descriptive statistics and a McNemar test to evaluate the impact of observerships on career choice. Finally, we used descriptive statistics to assess students' appreciation of the observerships. The level of significance for the analysis was set at $p \leq 0.05$. We used SPSS, version 25.0 (IBM Corp.) to conduct the analyses.

\section{Qualitative}

For each open-ended question, we used inductive datadriven thematic analysis following the method of Miles and colleagues. ${ }^{9}$ We chose this method as it allows closer interaction with the data and, therefore, the students' views. The first 3 authors (M.T.S., M.C., S.B.) condensed the data. To allow familiarization with the data set, 2 independent readings were performed. Each reviewer then independently identified usable sentences from each student in accordance with the given question. Using a semantic approach, each reviewer identified themes that related most closely to the data.

The reviewers then met to achieve consensus on identified themes and to create a codebook of the themes' definitions. Conflicting conclusions were resolved through literature-based discussions. A theme was defined as a recurring inclusive representation of the student's views about a given subject. The final list of themes was to be inclusive of all the students' views, and all themes were to be mutually exclusive. This ensured the reliability and validation of the theme list for each question. The reviewers then independently identified the themes involved in each student's response. A second meeting was held to reach consensus on thematic identification. This meeting also allowed a second validation of the themes. Using descriptive statistics, the reviewers quantified each theme to verify redundancy and saturation. This information, along with additional quotes, is provided in Appendix 1 (available at www.canjsurg. ca/lookup/doi/10.1503/cjs.019419/tab-related-content).

This initiative aimed to allow a more comprehensive perspective for further research and for other observership initiatives. Quotes are provided to enhance the understanding of the phenomenon. Forward- and backtranslation of the quotes, originally written in French, was done, and the translations were approved by all researchers involved in the analysis.

\section{Ethics approval}

The Ethics Review Board of the Université de Montréal waived the necessity for ethics approval as this study qualified as a curriculum-evaluation project. We obtained written informed consent from the participants before they completed the survey. Participants were able to withdraw consent at any time by communicating with the research team.

\section{Results}

Of the 316 observerships offered, 204 were chosen by students. The surgical specialty and the type of observership influenced the students' selection (Table 1). Observerships that offered operating room exposure were chosen by a higher proportion of participants, as were cardiac surgery, otolaryngology and pediatric subspecialities.

A total of 157 students provided consent and completed at least 1 survey. Of the 157, 57 answered only the preintervention survey and 15 answered only the postintervention survey and were therefore excluded from the analysis. Eighty-five students answered both surveys. The majority of students were female $(60[70 \%])$ and had done a prior surgical observership (58 [68\%]) (Table 2).

There were no differences in the students' characteristics or the observership chosen according to the number of surveys completed (Table 2). As students who did not answer at least 1 survey did not provide consent, no data on their characteristics were collected.

\section{Impact of observership on choice of surgical career}

\section{Quantitative}

When asked to list every specialty (medical and surgical) in which they were interested, most students reported having an interest in a surgical specialty before $(72[85 \%])$ and after (68 [80\%]) participating in the observership program. Students who had participated in a prior surgical observership were more likely to have a surgical interest both before $(54 / 58$ [93.1\%]) $(p=0.002)$ and after $(51 / 58$ [88\%]) $(p=0.04)$ the current observership. Few students changed 
Table 1. Distribution of the observerships offered and chosen

\begin{tabular}{|c|c|c|c|}
\hline Variable & $\begin{array}{l}\text { Offered } \\
n=316\end{array}$ & $\begin{array}{c}\text { Chosen; no. (\%) } \\
\text { of offered } \\
n=204\end{array}$ & $p$ value* \\
\hline Type & & & $<0.001$ \\
\hline Operating room & 226 & 166 (73.4) & \\
\hline Outpatient clinic & 73 & $30(41.1)$ & \\
\hline $\begin{array}{l}\text { On-call day/scope/minor } \\
\text { surgery }\end{array}$ & 17 & $8(47.0)$ & \\
\hline Duration & & & 0.8 \\
\hline Full day & 278 & $180(64.7)$ & \\
\hline Half-day & 38 & $24(63.2)$ & \\
\hline Specialty & & & $<0.001$ \\
\hline Cardiac surgery & 48 & $42(87.5)$ & \\
\hline Otolaryngology & 17 & $14(82.4)$ & \\
\hline Pediatric subspecialty & 86 & 63 (73.3) & \\
\hline Neurosurgery & 6 & $4(66.7)$ & \\
\hline General surgery & 52 & $32(61.5)$ & \\
\hline Orthopedic surgery & 13 & $7(53.8)$ & \\
\hline Plastic surgery & 47 & $25(53.2)$ & \\
\hline Thoracic surgery & 21 & $8(38.1)$ & \\
\hline Urology & 26 & $9(34.6)$ & \\
\hline
\end{tabular}

Table 2. Characteristics of students and observerships chosen

\begin{tabular}{|c|c|c|c|}
\hline \multirow[b]{2}{*}{ Characteristic } & \multicolumn{2}{|c|}{$\begin{array}{c}\text { Survey answered, no. (\%) of } \\
\text { students* }\end{array}$} & \multirow[b]{2}{*}{$p$ value } \\
\hline & $\begin{array}{c}\text { Pre- or } \\
\text { postintervention } \\
n=72\end{array}$ & $\begin{array}{l}\text { Both } \\
n=85\end{array}$ & \\
\hline Female sex & $47(65)$ & $60(70)$ & $0.48 \dagger$ \\
\hline Mean age, $\mathrm{yr}$ & 21.5 & 21.6 & $0.8 \neq$ \\
\hline Level of training & & & $0.3+$ \\
\hline Premedical & $25(35)$ & $35(41)$ & \\
\hline First year & $26(36)$ & $21(25)$ & \\
\hline Second year & $21(29)$ & $29(34)$ & \\
\hline Prior surgical observership & $40(56)$ & $58(68)$ & $0.2+$ \\
\hline Type of observership & & & $0.9+$ \\
\hline Operating room & $60(83)$ & $70(82)$ & \\
\hline Outpatient clinic & $10(14)$ & $14(16)$ & \\
\hline $\begin{array}{l}\text { On-call day/scope/minor } \\
\text { surgery }\end{array}$ & $2(3)$ & $1(1)$ & \\
\hline Observership duration & & & $0.1+$ \\
\hline Full day & 67 (93) & $72(85)$ & \\
\hline Half-day & $5(7)$ & $13(15)$ & \\
\hline Cardiac surgery & $21(29)$ & $23(27)$ & $0.9+$ \\
\hline $\begin{array}{l}\text { *Except where noted otherwise } \\
\text { † } \chi^{2} \text { test. } \\
\text { \& Student } t \text { test. }\end{array}$ & & & \\
\hline
\end{tabular}

their interest after the observership either toward $(n=3)$ or away from $(n=4)$ a surgical specialty. Four students reported being indecisive after the observership. However, when asked directly what the impact of the observership was on their career choice, most students reported being more interested in a surgical career (41 [48\%]) or having their interest in a surgical career confirmed (27 [32\%]).
Two students (2\%) reported diminished interest, and 14 (16\%) reported no impact on interest.

\section{Qualitative}

Factors taken into consideration by students in deciding on a career were divided into 4 themes: lifestyle, type of practice, skills required and work environment. Students who reported no impact from the observership or diminished interest in a surgical career desired a lifestyle that would allow them to prioritize their family. They discovered that the actions surgery required did not correlate with the practice they were looking for. The observership also allowed them to observe the skills required to progress into a surgical career, which did not correspond to the ones they perceived they possessed, as illustrated by the following quote: "I do not believe I am patient enough" (student 65).

Students who reported increased or confirmed interest in a surgical career after the observership were also concerned with having a balanced lifestyle, although this was not identified as a priority. The type of practice they aspired to was congruent with their perception of a surgical career. The skills required were of minor concern for these students, and, when expressed, they were compatible with those demonstrated by the surgeon.

Factors influencing students' career choices were also mirrored by their perceptions of the field of surgery. These perceptions were divided into 4 themes: pace, climate, patient-doctor relationship and type of practice. Before the observership, most students expressed negative perceptions of the surgical domain throughout the 4 themes. Students described surgery using depreciative terms, such as "A fast-paced field that requires long hours with little time for breaks" (student 17). Students described the climate using similar language, with the terms "competitive" and "stressful" often being mentioned. Although students had a positive attitude toward the type of practice surgery allowed, especially with its direct impact on patients, most had a negative perception of the patientdoctor relationship.

Sixty-four students $(75 \%)$ stated that their perceptions of the surgical domain remained unchanged after the observership. This was mirrored by the qualitative analysis of the responses of students who had diminished interest or no change in their interest in a surgical career. However, students who had increased or confirmed interest in a surgical career reported a changed perception of the surgical domain for all the themes. They described a more convenient pace and friendly climate, as illustrated by this quote: "The collegiality and humour I witnessed during my observership allowed me to ease my expectations of the surgical field" (student 49). Students perceived the patient-doctor relationship as meaningful and positive. For example, 1 student was "pleasantly surprised by surgeons' closeness with their patients. Caring was of the 
highest importance to establish a trusting relationship" (student 127). Students retained their positive perception of the type of practice surgery allowed and its concrete impact on the patient. Additional information is available in Appendix 1, Table S1.

\section{Appreciation of observership}

\section{Quantitative}

Most students mentioned having enjoyed (24 [28\%]) or loved (53 [62\%]) their experience; 8 (9\%) were neutral. No student reported a negative experience. Most students (80 [94\%]) reported having achieved their personal goals. Of the 8 students who were neutral toward their experience, only 2 reported not having achieved their goal in the yes/no question. One of these students mentioned he would have liked to have observed an operation (although he had booked an outpatient clinic day), and the other did not provide an explanation. The remaining 3 students who did not achieve their personal goals for the observership reported having enjoyed $(n=2)$ or loved $(n=1)$ their experience.

\section{Qualitative}

The most frequent objective of participants was intellectual curiosity, defined as learning in the field of surgery for pure personal interest. Students also wanted to learn more about the daily work of a surgeon, defined as the activities, tasks and responsibilities of practising surgeons. Some students mentioned using the observership opportunity to guide their career choice and to learn more about the domain for academic purposes.

Concerns were also expressed regarding the observership experience, with the most frequent being a lack of knowledge and its consequences. One student expressed a potential social repercussion of this fear: "Not to have sufficient knowledge, to look uninformed, not being intelligent enough to be in surgery" (student 17). Students were also concerned with interacting with a surgical team and with the quality of the exposure they would receive. They were also apprehensive about a physical response, such as fainting in the operating room, to situations they would experience. Additional information is available in Appendix 1, Table S2.

A positive experience was characterized by the surgeon's attitude toward the student and consistent knowledgesharing. These themes seemed to be related and were not limited to the surgeon: "The teaching done by surgeons and the rest of the team makes all the difference" (student 112). Direct exposure (in observing) and indirect exposure (in receiving appropriate explanations) were important to the students. A successful day also required the team to be welcoming to the student. This enabled students to feel included and accepted. Moreover, students mentioned that their willingness to participate was in part responsible for the success of their experience.

\section{Discussion}

Overall, a student-led surgical observership lasting 1 day or half a day led to increased interest in a surgical career on the part of most preclinical medical students. This was linked qualitatively with contrasting personal traits and a change of perception of the field of surgery. Most students reported a positive observership experience that also met their objectives. Observerships with operating room exposure as well as those in cardiac surgery, otorhinolaryngology and pediatric subspecialities were more often selected.

Although clinical observerships are commonly organized by medical student associations with the aim of, among other objectives, informing career choices, there is a paucity of literature describing such structured programs in surgery. ${ }^{10}$ Early exposure to a specific medical field benefits students in several ways. In addition to influencing academic results positively and enhancing students' curiosity, preclinical observerships encourage students to choose their career path. ${ }^{11}$ Kozar and colleagues ${ }^{12}$ showed that vocation choices were shaped above all by observerships in preclinical settings. Importantly, an observership offers medical students the opportunity to explore the daily activities within a practice and to learn from mentors in a field. Hence, preclinical observerships play a pivotal role in career decision-making. ${ }^{10}$ The considerable impact of early exposure is particularly relevant currently given the decrease in surgical recruitment across Canada., 5

In our study, most students reported increased or confirmed interest in a surgical career after their observership, which is consistent with previous studies. ${ }^{13,14}$ However, in line with a study assessing a similar student-led initiative in geriatric medicine, ${ }^{15}$ we did not observe a significant change in the students' choices of surgical specialties after the observership. This outcome was expected given the high proportion of students reporting an interest in surgery before their observerships, which resulted in a plateau effect. Although it has been suggested that a significant change could be detected in a larger study population, ${ }^{15}$ we believe that the selection of participants has a greater influence on results. As samples are often composed of participants presenting an interest in the specialty, changes would be more difficult to identify, even in a larger sample.

Our results highlight key differences between students' reported interest in surgery, their life and career priorities, and their self-perception of their skills. These findings suggest that the impact of observerships on career choices may be somewhat related to factors intrinsic to the students. This is further suggested by the fact that students with increased or confirmed interest in surgery after their observership reported changes in their perceptions, whereas perceptions remained unchanged in students who reported no impact of the observership on their interest in a surgical career or diminished interest. Hence, students with increased interest may be inherently attracted to a 
surgical career, and a positive observership experience may act as a trigger toward pursuing a career in this field. Similar results regarding students' perceptions of surgery were reported by Schmidt and colleagues. ${ }^{7}$ As students' misconceptions regarding surgeons and a career in surgery have a negative influence on their choices, ${ }^{7}$ breaking these stereotypes through observership programs may lead students to consider surgical specialties as a possible career choice, which would potentially result in more applications to these residency programs. ${ }^{7}$

Conflicts with class schedules may have played a role in our participants' selecting observerships with operating room exposure, as well as those in cardiac surgery, otorhinolaryngology and pediatric subspecialities. In this regard, we cannot confirm which type of exposure - operating room, ward or outpatient clinic - was most valuable for students; further study is needed to answer this question. Also, most factors identified by students as contributing to the success of their experience were related to the environment and the surgical team's attitude. Further study is needed to capture surgeons' point of view to better understand the factors contributing to a successful observership.

Schmidt and colleagues ${ }^{7}$ stressed the indisputable role of a positive mentorship in students' training. Thus, the combination of students' and surgeons' perceptions of observerships and of the features leading to a successful observership may result in enhanced positive results of further observership programs, thus promoting interest in surgery.

Although we did not carry out a formal cost analysis, this student-initiated program thrives on the participation of volunteer students and surgeons. Therefore, our findings suggest that GICUM's observership program is an efficient and inexpensive vehicle for providing medical students with early, positive exposure to surgery.

\section{Limitations}

Our sample was small and limited to a single institution, which affects the generalizability of our results. Selection bias might have affected our results given that students who decided to take part in the observership program and those who responded to both the pre- and postintervention surveys may have differed from other students. Although not all students were interested in surgery before the observership, the small number of participants did not allow a stratified analysis. Therefore, we relied on selfidentification via a semantic differential scale to identify students who did not have increased interest in a surgical career after the observership to differentiate students.

Most students with surgical exposure before this study obtained it from the GICUM observership program in previous years. Although this limitation undermined our capacity to observe significant differences, it shows the retention capacity of the program. Moreover, given the variety of observerships offered, standardization of exposure was unfeasible. However, the fact that many of our participants chose full-day observerships with operating room exposure mitigates the impact of this heterogeneity. The minority of participants who did observerships in an outpatient setting, although not exposed to surgical interventions, were able to learn about the perioperative aspects of surgical practice.

Finally, this study addresses students' current perceptions of the field of surgery and their future career. There is no clear evidence that the GICUM observership program will affect their career choices in the later stages of their studies, as no long-term follow-up questionnaires were completed. Prospective longitudinal studies are required to confirm the impact of observership programs on residency choices.

\section{Conclusion}

The GICUM observership program is a low-cost, peerinitiated initiative that allowed preclinical medical students to gain a positive introduction to surgery while breaking stereotypes of the surgical field early in the medical curriculum. This experience should provide a better understanding of surgery for students, enabling them to consider this domain and potentially influencing their residency application. Future steps are to evaluate surgeons' perceptions of observerships and the long-term effect of the program. This information will help build similar curriculums to influence preclinical students positively in their career decision.

Affiliation: From the Department of Surgery, Université de Montréal, Montréal, Que.

Competing interests: None declared.

Contributors: All authors designed the study. M. ThiviergeSouthidara, M. Courchesne and S. Bonneau acquired and analyzed the data and wrot e the manuscript, which S. Bonneau, M. Carrier and $M$. Henri critically revised. All authors gave final approval of the article to be published.

Content licence: This is an Open Access article distributed in accordance with the terms of the Creative Commons Attribution (CC BYNC-ND 4.0) licence, which permits use, distribution and reproduction in any medium, provided that the original publication is properly cited, the use is noncommercial (i.e., research or educational use), and no modifications or adaptations are made. See: https://creativecommons. org/licenses/by-nc-nd/4.0/.

\section{References}

1. Bland KI, Isaacs G. Contemporary trends in student selection of medical specialties: the potential impact on general surgery. Arch Surg 2002;137:259-67.

2. Peel JK, Schlachta CM, Alkhamesi NA. A systematic review of the factors affecting choice of surgery as a career. Can 7 Surg 2018;61: 58-67.

3. Simoes RL, Dorigatti AE, Silveira HJV, et al. Trauma leagues - a novel option to attract medical students to a surgical career. World $\mathcal{F}$ Surg 2018;42:549-56. 
4. Austin RE, Wanzel KR. Exposure to plastic surgery during undergraduate medical training: a single-institution review. Plast Surg (Oakv) 2015;23:43-7.

5. National data on CMG applicants and quota in the R-1 match by disciplines (first iteration only). Ottawa: Canadian Resident Matching Service; 2018.

6. Marschall JG, Karimuddin AA. Decline in popularity of general surgery as a career choice in North America: review of postgraduate residency training selection in Canada, 1996-2001. World 7 Surg 2003;27:249-52.

7. Schmidt LE, Cooper CA, Guo WA. Factors influencing US medical students' decision to pursue surgery. 7 Surg Res 2016;203:64-74.

8. Creswell JW, Plano Clark VL. Designing and conducting mixed methods research. 3rd ed. Thousand Oaks (CA): SAGE Publications; 2018.

9. Miles MB, Huberman AM, Saldaña J. Qualitative data analysis: a methods sourcebook. 3rd ed. Thousand Oaks (CA): SAGE Publications; 2014.
10. Penciner R. Emergency medicine preclerkship observerships: evaluation of a structured experience. CFEM 2009;11:235-9.

11. Elnicki DM, Halbritter KA, Antonelli MA, et al. Educational and career outcomes of an internal medicine preceptorship for first-year medical students. 7 Gen Intern Med 1999;14:341-6.

12. Kozar RA, Lucci A, Miller CC, et al. Brief intervention by surgeons can influence students toward a career in surgery. 7 Surg Res 2003; 111:166-9.

13. Carter MB, Larson GM, Polk HC Jr. A brief private group practice rotation changes junior medical students' perception of the surgical lifestyle. Am F Surg 2005;189:458-61.

14. Xu X, Wang Z, Pan H, et al. One-week experience in the general surgery outpatient clinic for preclinical medical students. F Surg Educ 2012;69:599-604.

15. You P, Leung M, Xu VYY, et al. Pre-clerkship observerships to increase early exposure to geriatric medicine. Can Geriatr 7 2015;18: $225-30$. 